\title{
Erratum to: Multiple Response Optimization of a HPLC Method for the Determination of Enantiomeric Purity of S-Ofloxacin
}

\author{
Valliappan Kannappan · Sai Sandeep Mannemala
}

Published online: 16 July 2014

(C) Springer-Verlag Berlin Heidelberg 2014

\section{Erratum to: Chromatographia}

DOI 10.1007/s10337-014-2699-4

Unfortunately, during the production process of this article the following mistakes occurred.

1. The line "The monograph of $\mathrm{n}$ is official",-1st page, 2nd column, 24th line-should read as "The monograph of ofloxacin is official".

2. The line "The determination of $n$ enantiomers" -1 st page, 2nd column, 28th line-should read as "The determination of ofloxacin enantiomers".

3. Figure 1, legend is printed incorrectly as "Structure of n enantiomers". The correct figure legend should be "Structure of ofloxacin enantiomers".

4. The line "HPLC methods reported for determination of $\mathrm{n}$ enantiomers." -2nd page, 1st column, 3rd and 4th line-should read as "HPLC methods reported for determination of ofloxacin enantiomers."

5. The line "and quantitation of the $\mathrm{n}$ enantiomers,"-2nd page, 1st column, 12th and 13rd line-should read as "and quantitation of the ofloxacin enantiomers".

The online version of the original article can be found under doi:10.1007/s10337-014-2699-4.

V. Kannappan $(\bowtie) \cdot$ S. S. Mannemala Department of Pharmacy, Faculty of Engineering and Technology, Annamalai University, Annamalai Nagar, Chidambaram 608002, Tamil Nadu, India

e-mail: vallikonnect@gmail.com 